On Law and Reason 


\title{
Law and Philosophy Library
}

\section{VOLUME 8}

\author{
Managing Editors
}

FRANCISCO J. LAPORTA, Department of Law, Autonomous University of Madrid, Spain

ALEKSANDER PECZENIK ${ }^{\dagger}$, Department of Law, University of Lund, Sweden FREDERICK SCHAUER, John F. Kennedy School of Government, Harvard University, Cambridge, Mass., U.S.A.

Former Managing Editors

AULIS AARNIO, MICHAEL D. BAYLES ${ }^{\dagger}$, CONRAD D. JOHNSON ${ }^{\dagger}$, ALAN MABE

\section{Editorial Advisory Board}

AULIS AARNIO, Secretary General of the Tampere Club, Finland ZENON BAŃKOWSKI, Centre for Law and Society, University of Edinburgh

PAOLO COMANDUCCI, University of Genoa, Italy

ERNESTO GARZÓN VALDÉS, Institut für Politikwissenschaft, Johannes Gutenberg Universitat Mainz

JOHN KLEINIG, Department of Law, Police Science and Criminal Justice Administration, John Jay College of Criminal Justice, City University of New York

NEIL MacCORMICK, European Parliament, Brussels, Belgium

WOJCIECH SADURSKI, European University Institute, Department of Law, Florence, Italy

ROBERT S. SUMMERS, School of Law, Cornell University

CARL WELLMAN, Department of Philosophy, Washington University

For other titles published in this series, go to www.springer.com/series/6210 
Aleksander Peczenik

On Law and Reason

旬 Springer 
Aleksander Peczenik

Lund University

Sweden

ISBN 978-1-4020-8729-5

e-ISBN 978-1-4020-8730-1

Library of Congress Control Number: 2008931006

(C) 2009 Springer Science + Business Media B.V.

No part of this work may be reproduced, stored in a retrieval system, or transmitted in any form or by any means, electronic, mechanical, photocopying, microfilming, recording or otherwise, without written permission from the Publisher, with the exception of any material supplied specifically for the purpose of being entered and executed on a computer system, for exclusive use by the purchaser of the work.

Printed on acid-free paper

987654321

springer.com 


\title{
Preface to the second edition of Aleksander Peczenik: On Law and Reason
}

\begin{abstract}
Aleksander Peczenik unexpectedly died in 2005 at the age of 68. At that time, he was still very active both as the chairman of the IVR (International Association for Philosophy of Law and Social Philosophy) and as a scientist.

During his prolific scientific career, Peczenik wrote several books, and it is a hazardous enterprise to pick out one of them as the most important one. If this hazardous enterprise needs to be undertaken, however, On Law and Reason would be a responsible choice. In this book Peczenik has tried to bring together many strands of his thought on the nature of legal justification and on the nature of law. Therefore it is a fitting tribute to the scientist Aleksander Peczenik that this work appears in a second edition. The publication of this second edition gives a new public the opportunity to get to know the insights of Peczenik about legal reasoning. What would in the eyes of Peczenik probably be more important is that the public could also learn about Peczenik's continuous strive for better insight that is illustrated by the main text and by the numerous asides interwoven throughout it.

On Law and Reason first appeared in 1989 as an extended and improved version of the Swedish work Rätten och förnuftet. It also builds on earlier work with Aarnio and Alexy and on his book The Basis of Legal Justification. In this sense it is the synopsis of a line of research that has extended over at least a decade. However, Peczenik would not have been himself if this synopsis would have meant the end of his intellectual efforts in this domain. New developments in the field of logic that fitted well with what he had tried to express with less sophisticated logical means sparkled his enthusiasm and inspired him to new work in which these developments were incorporated. ${ }^{1}$ Aulis Aarnio, with whom Peczenik cooperated for a long time in run up to On Law and Reason, wrote a lucid preface to the first edition of this work, in which he situates it in the intellectual setting that prevailed when the book appeared. I will not attempt to redo what Aarnio already did in a satisfactory way.
\end{abstract}

\footnotetext{
${ }^{1}$ In particular A Peczenik, 'Jumps and Logic in the Law', in H Prakken and G Sartor (eds), Logical Models of Legal Argumentation, Dordrecht: Kluwer Academic Publishers 1997, 141-174 and JC Hage and A Peczenik, 'Law, Morals, and Defeasibility', Ratio Juris 13 (2000), 305-325. An updated recapitulation of his views can also be found in A Peczenik, Scientia Juris. Legal Doctrine as Knowledge of Law and as a Source of Law, vol. 4 of 'A Treatise of Legal Philosophy and General Jurisprudence', Dordrecht: Springer 2005.
} 
Instead I will try to point out how Peczenik's thoughts developed after the first edition of On Law and Reason, taking in new scientific insights, but without abandoning what he wrote in this important book.

'This is an outline of a coherence theory of law. Its basic ideas are: reasonable support and weighing of reasons. All the rest is commentary.'

These words at the beginning of the preface should be taken very seriously.

The first thing to notice is that Peczenik's theory is a coherence theory. This means that Peczenik rejected the idea of foundations that are beyond discussion. Everything may be doubted, including the ideas that everything may be doubted and that coherentism is the way to deal with these doubts. This willingness to draw everything into a reasonable discussion was a central feature of Peczenik's scientific work, but also very characteristic for his personality. Although Peczenik would have been prepared to discuss the desirability of this constructive criticism, he might have found it impossible to abandon it, because this attitude was so characteristic for the person Peczenik.

A proper understanding of Peczenik's approach to coherentism requires that one distinguishes between what Raz called epistemic and constitutive coherentism. ${ }^{2}$ In epistemic coherentism, coherence is treated as a test whether something qualifies as knowledge of some object domain. In constitutive coherentism, coherence is treated as a characteristic of a domain. Applied to the law, the distinction would boil down to it that according to epistemic coherentism, a theory of the law can only count as knowledge of the law if it is (sufficiently) coherent. According to constitutive coherentism coherence would be a characteristic of the law itself, and not merely of knowledge. A typical example of constitutive coherentism applied to the law would be Dworkin's theory of law as integrity. ${ }^{3}$ For constitutive coherentism, the traditional epistemic literature on coherence ${ }^{4}$ would be irrelevant, because it dealt with a different matter. ${ }^{5}$

Peczenik would disagree, however. He adhered to epistemic work on coherence to develop a theory about the nature of the law. His theory is, as he stated himself in the preface, a coherence theory of law, not of knowledge of the law. In On Law and Reason he did not elaborate this theme, but in a later paper $^{6}$ the issue was addressed explicitly. There Peczenik wrote that '... the law is what the most coherent theory of everything says it is' (italics added - JH). Here the traditional order of ontology and epistemology is turned around. According to this traditional order, first we have a reality and second and derived we have theories about reality, which

\footnotetext{
${ }^{2} \mathrm{~J}$ Raz, 'The Relevance of Coherence', in J Raz, Ethics in the Public Domain, Oxford: Clarendon Press 1994, 277-326.

${ }^{3} \mathrm{R}$ Dworkin, Law's Empire, London: Fontana 1986.

${ }^{4}$ E.g. L Bonjour, The Structure of Empirical Knowledge, Cambridge: Harvard University Press 1985 and K Lehrer, Theory of Knowledge, 2nd ed., Boulder: Westview Press 2000.

${ }^{5}$ Raz, The Relevance of Coherence, 279.

${ }^{6}$ A Peczenik and JC Hage, 'Legal Knowledge about What?' Ratio Juris 13 (2000), 325-345.
} 
under ideal circumstances amount to knowledge. Reality does not depend on our knowledge of it, while knowledge does depend on reality. For the law, this traditional order is turned around: first we have knowledge, or - probably better - a justified theory, and second and derived we have the object of this theory. The nature of legal reality depends on our justified theories about it, rather than the other way round. Although this is not explicitly dealt with in the paper in question, I think that this reversed order has to do with the fact that the law is part of social reality, and that in the case of social reality, the facts depend - in a very complex way - on our views about them, rather than the other way round.

A consequence of Peczenik's coherentism is that he needed a criterion for coherence. For the rather complicated theory exposed in On Law and Reason, Peczenik used the results of a paper he co-wrote with Alexy. ${ }^{7}$ Although he never abandoned the views expressed there, he was quite enthusiastic about the implications of the view that a good coherent theory would be a theory of everything. 'Everything' does not only include all traditional objects of knowledge, such as the physical world and its laws, but also the social world, the realm of the ought, including morality, and - what is for the present purposes the most relevant - the standards for theory adoption and rejection. If a coherent theory includes these standards, coherence requires that it also includes those additional beliefs that should rationally be adopted, and that it does not include those additional beliefs that should rationally be rejected. This implies that the standards for belief adoption and rejection need no more be part of a specification of coherence, but can be left over to the coherent theory itself. The only remaining demand for coherence is that a coherent theory includes everything that should, according to this theory itself, be accepted, and does not contain what should, according to this theory itself, be rejected. ${ }^{8}$ Although this abstract view on coherence does not take away the difficulties of specifying what should be accepted, it moves these difficulties from the definition of coherence to the specification of a coherent theory. In his last book, Peczenik seemed to adopt this view by stating that '... Alexy-Peczenik coherence criteria appear to be a part of the acceptance set of a juristic theory of law rather than a general philosophical theory of coherence'.

A crucial aspect of Peczenik's coherentism is the view that coherence is based on reasonable support and the weighing of reasons. When Peczenik wrote On Law and Reason the paradigm of rationality was still the deductively valid argument. The problem with these arguments is that the strength of the argument chain is inversely correlated with the plausibility of the premises. For instance, the argument:

\footnotetext{
${ }^{7} \mathrm{R}$ Alexy and A Peczenik, 'The Concept of Coherence and its Significance for Discursive Rationality', Ratio Juris 3 (1990), 130-147.

${ }^{8}$ JC Hage, 'Law and Coherence', Ratio Juris 17 (2004), 87-105.

${ }^{9}$ Scientia Juris, 147.
} 
All thieves are punishable

John is a thief

John is punishable

is impeccable from the logical point of view. However, the first premise is likely to be false. Although in general thieves are punishable, not all thieves suffer from this liability. To say it simply, the first premise is stated too strongly, with as consequence that it is not true anymore. However, this strong premise is necessary to make the argument leading from the premise that John is a thief to the conclusion that John is punishable deductively valid. If the first premise is replaced by

In general thieves are punishable

the conclusion that John is punishable does not follow deductively but 'only' defeasibly. This talk about defeasible reasoning has now become more fashionable in legal theory, but when On Law and Reason was published, the application of so-called nonmonotonic logic (the kind of logic most suitable to deal with defeasibility) to legal reasoning was still in its infancy. Peczenik was one of the first to emphasize that legal arguments support their conclusions, but that they are usually not valid according to the standards for deductive logic. One reason for this is that many arguments provide reasons for their conclusions, but that these reasons still have to be balanced against other reasons, pleading against the same conclusion. ${ }^{10}$ Another reason is that rules are often 'overinclusive' 11 and that their consequences should not apply in all cases that fall strictly spoken within their scope.

The idea that legal reasoning is defeasible was already a central feature of On Law and Reason. When the logical tools to deal with defeasible reasoning became more widely available in the nineties, Peczenik immediately embraced them ${ }^{12}$ and put them to use to say in a more modern terminology what he had already said before, namely that in the law arguments support their conclusions without guaranteeing their truth. ${ }^{13}$ On Law and Reason is a book much too rich to discuss all its details, or even all the topics addressed in it. I can only urge the reader to look for himself how Peczenik elaborated the idea that the law is coherent and based on reasonable support and the weighing of reasons. Not necessarily because the reader should adopt all the views exposed in the book. That would even be against its spirit. If Peczenik were still alive, he would encourage the reader to develop his own ideas, in dialogue with what he wrote about these subjects. And then the reader should communicate his newly developed ideas to others, in order that they might continue this process of reasonable development of theories about the law and thereby also the law itself.

\footnotetext{
${ }^{10}$ This is the insight used by Dworkin to specify legal principles (as opposed to rules; R Dworkin, Taking Rights Seriously, London: Duckworth 1977, 24) and by Alexy to specify the operation of human rights (R Alexy, Theorie der Grundrechte, $3^{\mathrm{e}}$ Auflage, Frankfurt: Suhrkamp 1996, 71f).

${ }^{11}$ F. Schauer, Playing by the Rules, Oxford: Clarendon Press 1995, $31 \mathrm{f}$.

${ }^{12}$ See in particular the papers mentioned in note 1.

${ }^{13}$ Actually this has not only to do with the defeasibility of legal arguments, but also - as Peczenik recognized - with the provisional nature of their premises.
} 


\section{Preface}

This is an outline of a coherence theory of law. Its basic ideas are: reasonable support and weighing of reasons. All the rest is a commentary.

I am most grateful to many colleagues for extensive discussions and criticism concerning various ideas presented in this book, in particular to Aulis Aarnio, Robert Alexy and Horacio Spector. Others to whom I am indebted for comments are more numerous than it would be possible to mention here. I will do no more than to record my gratitude to the readers of the publisher whose penetrating remarks helped me to reorganise the manuscript.

A Scandinavian reader must be informed that the present book constitutes a modified version of my Swedish work Rätten och förnuftet. However, the content has been radically changed. I hope that the alterations make the main point of the work clearer. Especially, the key sections 2.3, 2.4, 3.2.4, 5.4, 5.8 and Chapter 4 are entirely new.

The book contains extensive examples of legal reasoning and reports of various moral and legal theories. Though relevant, this material could make it difficult for the reader to focus attention on the main line of argument. To avoid this, a smaller printing-type size has been chosen for such a background information.

Lund, 18 May, 1989

Aleksander Peczenik 


\section{Contents}

Introduction by Aulis Aarnio ………....................................................

1 The Dilema of Legal Reasoning: Moral Evaluation or Description of the Law?.

$1.1 \quad$ A Theory of Legal Reasoning ....................................................... 13

1.2 Legal Decision-Making and Evaluations ..................................... 14

1.2.1 Introduction. Subsumption in Clear and Hard Cases ............ 14

1.2.2 Interpretative Problems - Ambiguity, Vagueness and Value-Openess ......................................................... 16

1.2.3 Gaps in the Law ................................................................ 18

1.2.4 Evidence of Facts ............................................................. 20

1.2.5 Choice of a Legal Norm .................................................... 20

1.2.6 Choice of a Legal Consequence ....................................... 21

1.2.7 Obsolete Laws and Desuetudo ........................................... 22

1.3 The Concept "Legal Decision-Making".......................................... 22

1.4 Why do the Lawyers Need Special Interpretation Methods?............ 24

1.4.1 Expectation of Legal Certainty ........................................... 24

1.4.2 The Law and Democracy .............................................. 27

1.5 Legal Knowledge?................................................................ 33

1.5.1 Introductory Remarks on Theoretical

1.5.2 Legal Interpretatory Statements ....................................... 34

1.5.3 The Main Problem: Knowledge, Truth and
Rightness In Legal Reasoning......................................... 35

2 Rationality of Moral Judgments................................................... 39

2.1 Cognitivism and Non-Cognitivism .............................................. 39

2.2 Practical and Theoretical Meaning of Practical Statements............. 42

2.2.1 Practical Meaning......................................................... 42

2.2.2 More About Practical Meaning. Norms and the Will ........... 43

2.2.3 Theoretical Meaning of Practical Statements: 
2.2.4 Theoretical Meaning of Practical Statements:

L-, S- and D-rationality.

2.3 More About Theoretical Meaning of Practical Statements

Prima-facie Moral Statements

2.3.1 Criteria of Moral Goodness.......

2.3.2 General Theories of the Morally Good

2.3.3 Prima-facie Character of Moral Theories and Criteria

2.3.4 The Step From Theoretical Propositions to Prima-facie Practical Conclusions

2.3.5 Permissibility-Making Facts .................................................. 55

2.3.6 Claim-Making Facts................................................................ 57

2.3.7 Competence-Making Facts..................................................... 59

2.3.8 Complex Right-Making Facts ................................................ 60

2.4 Weighing and Balancing ………………………............................ 61

2.4.1 Principles and Values ............................................................... 61

2.4.2 All-Things-Considered Practical Statements ........................ 62

2.4.3 Weighing and Balancing of Principles ................................... 63

2.4.4 Weighing Rules ................................................................ 66

2.4.5 Final Act of Weighing and Balancing ................................. 67

2.4.6 A Step From Theoretical Propositions to Definitive Practical Statements?

2.4.7 The Step From Practical Statements To Theoretical Conclusions

2.4.8 Concluding Remarks Concerning Logical Relations Between Theoretical and Practical Statements ...... 76

2.5 Some Examples of the Role of Weighing in Moral Theories ............ 77

2.5.1 Introductory Remarks......................................................... 77

2.5.2 Weighing Preferences: Hare's Utilitarianism......................... 77

2.5.3 Weighing Practices: MacIntyre's Theory of Virtue................ 81

2.6 Examples of Weighing in Theories of Justice ..................................... 83

2.6.1 Justice, Equality and Weighing .............................................. 83

2.6.2 The Role of Weighing In John Rawls's Theory of Justice ................................................................... 86

2.6.3 The Role of Weighing In Robert Nozick's Theory of Justice ................................................................. 90

2.6.4 Some Concluding Remarks on Justice ………….................... 93

2.7 Support in Moral Reasoning …………………............................... 95

2.7.1 Gaps and Jumps in Moral Reasoning................................... 95

2.7.2 The Concept of a Jump …………………………................. 96

2.7.3 The Concept of a Reasonable Premise................................... 96

2.7.4 The Concept of Reasonable Support........................................ 97

3 Rationality of Legal Reasoning ......................................................... 99

3.1 Support of Legal Reasoning. Introduction and an Example ............ 99 
3.1.1 Fixity of Law. Extensive Support of Legal Reasoning...........

3.1.2 An Example of Extensively Supported

Legal Reasoning

3.1.3 An Example of Analysis of Legal Concepts the Concept of Adequacy

3.1.4 An Example of Substantive Reasons in the Law.

The Purpose of Protection. Influence of Moral Theories and Criteria.

3.1.5 An Example of Legal Authority Reasons.

Brief Remarks on Precedents

3.2 Analysis of Support in Legal Reasoning.

3.2.1 Legal Reasoning As a Dialogue. Reflective

Equilibrium and Hermeneutical Circle

3.2.2 Legal Reasoning As an Inference. An Example ................. 107

3.2.3 Legal Reasoning As a Reasonable Jump ............................ 109

3.2.4 Strong Support ............................................................ 110

3.2.5 Depth of Reasoning........................................................ 113

3.3 Legal Rationality and Legal Paradigm......................................... 115

3.3.1 Introductory Remarks on Legal Paradigm ......................... 115

3.3.2 Some Theories of Science ................................................... 115

3.3.3 Theory of Science and Legal Reasoning............................ 117

3.3.4 Certain Premises................................................................ 121

3.3.5 Presupposed Premises ....................................................... 124

3.3.6 Proved Premises of Legal Reasoning.................................. 126

3.3.7 Other Reasonable Premises of Legal Reasoning.................. 126

3.3.8 Reasonableness and Falsification........................................ 128

3.3.9 The Problem of Fundamental Justification of Legal Reasoning

4 The Ultimate Justification of Moral and Legal Reasoning ............... 131

4.1 Coherence............................................................................ 131

4.1.1 Introductory Remarks...................................................... 131

4.1.2 The Concept and Criteria of Coherence.............................. 132

4.1.3 Properties of the Supportive Structure ............................... 133

4.1.4 Properties of Concepts .................................................... 140

4.1.5 Properties of the Objects the Theory Deals With................. 143

4.1.6 Weighing and Balancing of Criteria of Coherence ............... 144

4.2 Coherence, Correctness and Truth .............................................. 145

4.2.1 Coherence and Rational Thinking..................................... 145

4.2.2 Coherence, Data, Presuppositions and Correctness ............. 146

4.2.3 Theories of Truth.............................................................. 147

4.2.4 More About the Correspondence Theory of Truth................ 149

4.2.5 Conclusions About Truth and Coherence ............................ 150

4.2.6 Truth and Correctness of Practical Statements .................... 152 
4.3 Rational Discourse ................................................................ 152

4.3.1 Introductory Remarks on D-Rationality............................ 152

4.3.2 Robert Alexy's Rules for Rational Practical Discourse........................................................... 154

4.3.3 Robert Alexy's Principles of Rationality ............................ 157

4.3.4 Robert Alexy's Rules For Rational

Legal Discourse............................................................... 158

4.4 Why Shall Legal Reasoning be Rational?..................................... 160

4.4.1 Introduction. Why Shall Theoretical Propositions

Be Consistent and Highly Coherent? ................................... 160

4.4.2 Why Shall Practical Statements Be

Logically Consistent?

4.4.3 Why Shall Practical Statements Be Highly

Coherent? Some Conceptual Reasons.

4.4.4 Some Conceptual Reasons for Rationality

of a Practical Discourse.

4.4.5 Why Shall Practical Statements Uttered

Within Legal Reasoning Be Rational? Some

Conceptual Reasons

4.4.6 The Concepts and Life ................................................... 167

4.4.7 Why Shall Practical Statements Be Highly

Coherent? Some Empirical and Technical Reasons.............. 168

4.4.8 Why Should a Discourse be Rational? Empirical, Technical and Universally-Pragmatic Reasons

4.4.9 Why Should Practical Statements Uttered

Within Legal Reasoning be Rational? Some

Further Reasons.

5 What is Valid Law?

5.1 What is a Valid Law? - Introductory Remarks

5.1.1 Starting Point: Rationality and Fixity ............................... 173

5.1.2 The Purpose of our Theory of Valid Law............................. 174

5.1.3 Normative Character of the Concept "Valid Law"................ 175

5.2 Law and Morality - On Natural Law ............................................ 176

5.2.1 Introductory Remarks..................................................... 176

5.2.2 An Example of Empirical Theory of Natural Law............... 178

5.2.3 Some Critical Remarks on Natural-Law Theories ................ 180

5.3 Law and Morality - Legal Positivism ........................................... 180

5.3.1 Hans Kelsen's "Pure" Theory of Law ................................. 180

5.3.2 Herbert Hart's Theory of Law ............................................ 186

5.3.3 The Institutionalist Legal Positivism................................... 190

5.3.4 Limitations of Classical Theories of Valid Law.................... 194

5.4 More about Law and Morality ..................................................... 195

5.4.1 Prima-facie Law and its Relation to Prima-facie

Morality 
5.4.2 The Justification of the Relation Between the Law and Prima-facie Moral Norms. Why Ought One to Follow the Law?

5.4.3 Weighing Legal Rules ........................................................ 203

5.4.4 All-Things-Considered Law as Interpreted Law.................. 203

5.4.5 The Relation Between the All-Things-Considered

Legal Norms and All-Things-Considered Moral Norms

5.4.6 Gaps in Interpreted Law. Legal Interpretation and Moral Criticism

5.4.7 The Right to Resist Oppression.

5.5 The Question of Existence of the Law. Legal Realism .................... 210

5.5.1 Introductory Remarks. Axel Hägerström's Philosophical Starting Points

5.5.2 Karl Olivecrona On Independent Imperatives and Their Functions

5.5.3 Tore Strömberg's Conventionalism .................................... 213

5.5.4 Alf Ross's Predictionism................................................. 214

5.5.5 Some Critical Remarks On Legal Realism ......................... 216

5.5.6 The Three Worlds................................................................. 218

5.5.7 Components of Valid Law................................................ 219

5.6 Norms as a Component of Valid Law ........................................... 220

5.6.1 Introductory Remarks On Legal Norms............................. 220

5.6.2 Internal Validity of Legal Norms ...................................... 222

5.6.3 External Validity of Legal System. Criteria

Concerning the Content of Norms ........................................ 224

5.6.4 Regulative Norms ............................................................... 225

5.6.5 Constitutive Norms ........................................................... 226

5.7 More About External Validity of Legal System.

Action as a Component of Valid Law ............................................ 231

5.8 Fact and Values in the Law ......................................................... 232

5.8.1 More About External Validity of Legal System:

Law-Making Facts............................................................ 232

5.8.2 Ought-Making Facts As Law-Making Facts ...................... 234

5.8.3 Evaluative Openness of Valid Law..................................... 236

5.8.4 The Basic Norm For the Law ............................................. 239

5.8.5 A Classification of Jumps and Transformations in Legal Reasoning........................................................ 244

5.9 One Right Answer to all Legal Questions?................................ 245

5.9.1 Introductory Remarks....................................................... 245

5.9.2 The Right Thesis .............................................................. 246

5.9.3 The Right Answer Thesis............................................... 249

5.9.4 The Incommensurability Thesis .......................................... 251

5.9.5 Existence of All-Things-Considered Law........................... 253

5.9.6 Some Remarks on "External Scepticism"........................... 254

5.9.7 Alexy on the Right Answer.............................................. 255 
6.1 Substantive Reasons and Authority Reasons.

The Sources of the Law....

6.1.1 Introductory Remarks................................................... 257

6.1.2 Substantive Reasons and Rationality ............................... 257

6.1.3 Authority Reasons and Fixity............................................ 259

6.1.4 Sources of Law ........................................................... 260

6.2 Must-Sources, Should-Sources and May-Sources of the Law.......... 261

6.2.1 Why Three Categories of Sources of Law? .......................... 261

6.2.2 Concepts of Must-, Should- and May-Source.................... 262

6.3 Norms Concerning the Sources of the Law ................................... 264

6.3.1 The Character of Source-Norms ......................................... 264

6.3.2 Complexity of the Swedish Doctrine of the Sources of Law ................................................................. 266

6.3.3 Are Substantive Reasons Sources of the Law? ................... 269

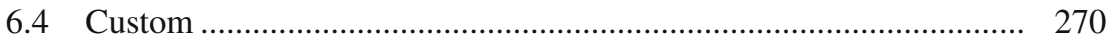

6.5 Precedent .............................................................................. 272

6.5.1 Introductory Remarks.................................................. 272

6.5.2 Ratio Decidendi and Rationality ...................................... 273

6.5.3 Why and To What Extent Ought One to Follow

Precedents?.................................................................... 274

6.5.4 Methods of Justifying Judicial Decisions .......................... 275

6.5.5 Coherence of Judicial Decisions ......................................... 278

6.5.6 The Role of Precedents in Swedish Law.............................. 280

6.6 Legislative Preparatory Materials ............................................... 282

6.6.1 Introductory Remarks..................................................... 282

6.6.2 Ratio Legis........................................................................ 282

6.6.3 Is Subjective Interpretation of Statutes Possible? ................ 283

6.6.4 Is Ratio-Legis Compatible with Democracy? ...................... 285

6.6.5 Should One Pay Attention to Preparatory Materials?........... 287

6.6.6 The Role of Preparatory Materials in Swedish

Law. General Remarks ..................................................... 289

6.6.7 The Role of Preparatory Materials in Swedish

Law. Some Source-Norms................................................. 292

6.7 Professional Juristic Literature................................................ 295

6.8 Foreign Laws...................................................................... 298

6.9 Draft Statutes and Formerly Valid Law........................................ 301

$7 \quad$ The Methods of Legal Reasoning ........................................................ 305

7.1 Reasoning Norms .................................................................. 305

7.1.1 Construction of Statutes in Hard Cases.............................. 305

7.1.2 Reasoning Norms ............................................................ 307

7.2 Logical, Literal and Systematic Interpretation.............................. 310

7.2.1 Logical and Quasi-Logical Interpretation ......................... 310 
7.2.2 Literal Interpretation ...................................................... 312

7.2.3 Systematic Interpretation ........................................... 314

7.3 Reduction, Restrictive Interpretation, Extensive

Interpretation and Creation of New Norms.................................... 317

7.4 Conclusion by Analogy ............................................................. 320

7.4.1 Introductory Remarks on Statutory Analogy ....................... 320

7.4.2 The Origin and Justification of Statutory Analogy .............. 321

7.4.3 Law-Analogy and Legal Induction ................................... 321

7.4.4 Argumentum e contrario .................................................. 322

7.4.5 The Choice Between Analogy and Argumentum e contrario .......................................................................... 323

7.4.6 Argumentum a fortiori....................................................... 328

7.5 Teleological Construction of Statutes ......................................... 329

7.5.1 The Basic Structure ...................................................... 329

7.5.2 Subjective and Objective Teleological Interpretation of Statutes .................................................. 330

7.5.3 Radical Teleological Interpretation of Statutes .................... 331

7.5.4 Teleological Interpretation of Statutes According to Ekelöf. Introductory Remarks ...................................... 333

7.5.5 Teleological Interpretation of Statutes According to Ekelöf. The Problem of Preciseness ................................ 334

7.5.6 Teleological Interpretation of Statutes According to Ekelöf. Multiple Goals .................................................... 337

7.5.7 Teleological Interpretation of Statutes According to Ekelöf. Restricted List of Interpretatory Methods and Sources of Law

7.5.8 Teleological Interpretation of Statutes According to Ekelöf. Conclusions ....................................................... 339

7.6 Solution of Collisions Between Legal Norms............................... 340

7.6.1 Collisions of Rules and Principles ...................................... 340

7.6.2 Collision Norms ............................................................ 342

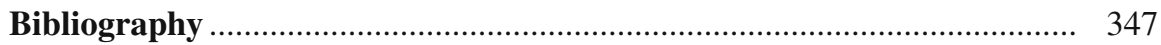

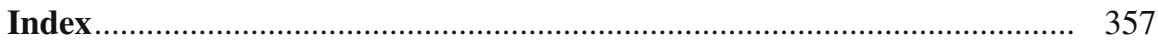




\title{
Introduction
}

\author{
Aulis Aarnio
}

In his book "Juridikens metodproblem" (Methodological Problems in Law), Aleksander Peczenik describes the concept of "neorealism" with the help of six criteria: (1) research in jurisprudence should utilise varied disciplines in law, philosophy and the social sciences; (2) these varied and multifaceted disciplines can and must be utilised particularly effectively in an analysis of the fundamental legal concepts (for example "valid law"); (3) the analysis should be deliberately neutral in respect to philosophical conflicts; (4) this type of analysis should be adapted to numerous examples of the use of concepts in law; (5) the author uses such an analysis as the point of departure for a description of established rules of legal interpretation and calls this "practical jurisprudence"; and (6) the analysis can also be used in a comparison between legal research and the established scientific disciplines.

The author calls jurisprudence that meets the conditions described above "juristic theory of law". It is "juristic", since it is based on legal research, and it is "theory" because it is more general and analytical than ordinary legal research. "Neorealism" is another term for this juristic theory of law. However, Peczenik does not approve of the view of Legal Realism which demands that legal research must avoid all loose and "metaphysical" concepts. It is the task of neorealism to specify what is valuable in legal research and alive in legal practice. Neorealism is constructive and not, as classical Legal Realism, destructive.

Since over ten years, Aleksander Peczenik has modified his theories in many ways. Yet, the basic attitude is the same as in the beginning of the 1970s. Also today, Aleksander Peczenik can be characterised as a neorealist. In the following, I shall seek to provide a general description of the legal, jurisprudential and philosophical background which renders Peczenik's neorealism understandable from another point of view than that he himself uses. My perspective is to a large extent that of a collaborator, as I have had the privilege to work together with Peczenik for almost fifteen years. This fact has both advantages and disadvantages for the present introduction. The advantage is that it makes it possible to "see" through Peczenik's conceptual apparatus, which is both technical and complex. Because of this, it is easier than it might otherwise have been to understand the sound basic ideas which colour his entire theoretical system. On the other hand, it is precisely this closeness as a collaborator that is a source of weakness. The introduction can, in this sense, become subjectively coloured. 
2. The purpose of this introduction is the following. First, I shall briefly define the concept of legal dogmatics and then I shall use this definition to analyse certain basic elements in the very complicated phenomenon known as legal interpretation. This will lead us to fundamental problems concerning legal truth and in legal knowledge. It is not possible to understand neorealism without entering into these cornerstones of Peczenik's world of ideas.

3. In the ordinary legal usage, the term "legal research" refers to at least four different types of scientific activity. We can distinguish between the history of law, the sociology of law, comparative jurisprudence and legal dogmatics. Of these, the last two are close relatives. The difference lies in the object of the activity: comparative law describes, analyses and explains legal norms in force in other countries, while legal dogmatics concentrates on a particular legal order. Sociology of law has a special position in the family of legal disciplines. It is not particularly interested in the interpretation of legal norms in force; instead, it concentrates on certain regularities in legal society, for example in respect of the behaviour of people, or the effects legal norms have in society. Sociology of law uses special research methods (empirical, statistical etc.). This means that there is a clear line of demarcation between legal dogmatics and sociology of law. On the other hand, sociology of law is closely related to history of law. The latter uses, in many respects, the same methods as does the former: it describes, analyses and explains historical material in the same way as does the sociology of law - or at least it can do so. The difference between the two disciplines lies in the object of inquiry. History of law is interested in the past, while the sociology of law focuses on the present society.

From the point of view of our analysis, the difference between sociology of law and legal dogmatics is central. Legal dogmatics is a typical interpretative discipline. It uses facts provided by sociology of law, but the interpretation itself has a nonempirical nature. According to normal usage, legal dogmatics has two functions: to interpret and to systematise legal norms. In Peczenik's book, systematisation is dealt with only as an implicit condition for legal interpretation.

On the other hand, legal dogmatics is legal dogmatics precisely due to the fact that it interprets and systematises legal norms. Legal dogmatics has this specific role in the division of labour in society. No other discipline offers practical legal life the same information. It is not, for example, the function of sociology of law. Systematisation in different areas (family law, other civil law, criminal law, and so on) is a necessary tool for all legal interpretation. As I shall argue later on, systematisation is the theoretical aspect of legal dogmatics. Systematisation plays the same role in legal dogmatics as the theoretical social sciences in sociology. From this point of view, legal interpretation is the practical aspect of legal dogmatics, and it is primarily directed towards practical goals. Interpretation can be compared to empirical research in the social sciences.

Theory and practice work together in all fields of science. Theoretical structure, by necessity, influences practice. Theoretical concepts, theories and so on are tools 
of the scientist. Just as the carpenter needs his hammer, saw and nails, the scientist needs his scientific tools. This is also the case in legal dogmatics. For this reason, interplay between interpretation and systematisation is inherent in all serious descriptions of legal dogmatics. Consequently, systematisation is implicit in everything Peczenik said about interpretation. At the end of this introduction, I shall attempt to explain certain aspects of this question.

4. The concept of "interpretation" has many senses. In the following, I use this concept to refer to a process where one must choose between different alternative meanings. Many factors can determine such a choice. They are all derived from everyday language, which is the medium used by the legislator. Language is open, vague, ambiguous and so on, and there are gaps and inner inconsistencies in law. To take an example, ambiguity lends richness to language and makes it possible for us to adapt ourselves to different circumstances. On the other hand, ambiguity is a very common origin of interpretation.

Schematically, the point of departure of interpretation can be described, as follows. Firstly, a statutory provision can have many possible interpretations. It is the task of the person interpreting the law to choose between them. Secondly, it may be unclear which of several provisions should be applied to a problematic case. This can be called the problem of qualification. In legal dogmatics, the first case is more common, as the point of departure is often an ambiguous text of law. In judicial practice, the situation is typically closer to the second case. For example in a criminal case, the problem can be to choose between different ways of describing the act, and thus between different penal provisions. Despite the differences, the nature of legal thought is the same in both cases. It is only the point of departure that distinguishes the two: a legal text or a concrete case.

5. Certain fundamental questions of legal interpretation can best be illustrated if one analyses the activity of the judge. It is a part of the role of the judge within the legal machinery to exercise the power to make decisions in all cases brought before him. This power has a necessary link with the coercion which is typical of law. Indeed, the law has been often defined as a coercive order. As a counterweight to his decision-making power, the judge has the obligation to decide all cases that are brought to the court. The judge must make a decision, even if he is not aware of the proper content of the law. And, as a consequence of the nature of everyday language, it is not possible for the judge to know immediately which solution is the lawful one. In such situations citizens in general and the litigants in particular naturally expect a solution that fulfils the demands for legal certainty. What, then, does legal certainty mean?

The reformer Olaus Petri provides certain indications in his judicial rules of 1540 which, even today, are an important measure in the Nordic concept of law. Olaus Petri took up arms against arbitrariness. According to him, arbitrary judicial activity did not serve the people. The meaning of "arbitrariness" was left open in his work. However, on the basis of an overall analysis of the judicial rules, it is possible to say that arbitrariness is the same thing as random elements in judicial activity. According to modern usage, this means that the judicial decision must be 
predictable; indeed, predictability is one of the fundamental conditions for human activity. If judicial decisions are unpredictable, it is impossible for citizens to make predictions related to their own future activity.

On the other hand, the avoidance of arbitrariness is not the only condition for legal certainty. In the Nordic legal culture, legal certainty also contains certain material demands. Already Olaus Petri referred to "the good and benefit of the common people" when he talked about avoiding arbitrariness. In Finish philosophy of law, Otto Brusiin has emphasised this side of the problem. Briefly, the material demands can be described in the following manner.

Let us assume that we are a party of a legal dispute. What - apart of predictability are our fundamental expectations regarding the court? Presumably, the majority of citizens in a democratic society would answer that they assume that the decision shall be both lawful and acceptable. The judge must make his decision in accordance with the law in force and, at the same time, take into consideration the values that are generally accepted in society. Thus, the concept of legal certainty involves two central elements, law and values or, in order to use everyday language, law and morality. This is particularly typical for the so-called welfare state. Aleksander Peczenik has grasped this point. For him, the connection between the legal and the moral is the central problem. The concept of legal certainty ties this connection with certain elementary and fundamental phenomena in society. The "alliance" between law and morality thus has deep roots in the legal culture. For this reason, analysis of the background of legal interpretation is always, in a way, a culture analysis.

6. How can a judge fulfil his duty to base his decisions on uncertain information and, at the same time, achieve maximal legal certainty? We have already observed that the judge must choose between different alternative interpretations of the law. However, it is not enough that he simply chooses and then announces the judgment. A justification must also be given for the judgment. Why? Even a few decades ago, all Western European countries were in many ways and to varying degrees authoritarian. Citizens blindly relied on authority, the church, the court system, the administrative machinery and so on. Especially after the Second World War, this faith in authority decreased. There are many clear signs of this development. Certain sociological studies in the United States and the OECD countries note that, among other things, only a minority of citizens have confidence in the administrative authorities. The same trend applies to the courts even though they continue to enjoy more confidence than other institutions in society. As Gunnar Bergholtz has noted, the demand for justification of decisions thus has its roots in the development of society. Authority on its own is no longer sufficient. Every institution, the courts included, must repeatedly regain the confidence of citizens, and this can only be done by giving justification for decisions. Reasons must be given for decisions, and citizens trust the reasons, not the decision alone. Thus it is not surprising that theory of law all over the world is today interested in legal interpretation and argumentation. These background factors also explain the basic components of Aleksander Peczenik's line of thought. The target of his analysis is always the process of justification. 
7. Justification can be examined in different perspectives. One can describe the process of interpretation. Doing this, theorists are interested in the so-called "context of discovery", that is, the way in which the decision came about. The other possibility is to explain why certain interpretation has been formulated. The explanation can be either causal or teleological. In the latter case, one attempts at making interpretation and interpretative process understandable. For example, one might refer to certain goals that necessarily bring about a certain type of decision. Aleksander Peczenik has chosen a third perspective, common in the international discussion, a perspective which can be called the "context of justification".

The problem of justification is complex. Legal theory can be interested in the factual structure or process of justification, typical for a court or legal dogmatics. To this extent, one might speak about the description of justification. There are considerable problems involved in this. The greatest is that the factual justification varies from one legal system to another. On the other hand, it is possible that a judicial decision is explicitly justified in one way even though it has been based on other grounds, not openly stated. However, it is not a task of legal theory to describe the justification of court decisions. Such a description belongs more to the sociology of law than to legal theory. In all sciences, the role of theory is to construct models to be used in practical activity. Everyday scientific work can then more or less fulfil the demands of the model, and theory has described the ideal which serves as the measure for what is (good) science. The same applies to legal theory as a theory of legal dogmatics or judicial activity. Aleksander Peczenik's work is a typical attempt to construct a model for judicial interpretation.

The model is not arbitrary. As we could note in connection with the analysis of the concept of legal certainty, this model of interpretation has deep roots in Western European culture. It corresponds to the most important expectations that people in our cultural circle have. Georg Henrik von Wright has said that such a model cannot be proven. It can only be more or less adequate. If a model as a theoretical construct violates common usage of language, framework of behaviour or implicit expectations, it cannot work in our culture.

8. There are two levels in Peczenik's model. He distinguishes between two different types of justification, (1) contextually sufficient justification and (2) deep justification, in other words justification of justification. The former describes what legal interpretation is. The latter states how we can justify the evaluation of legal interpretation as reasonable and beneficial for legal society. In contextually sufficient justification, we come across the concepts of "jump" and "transformation" which occupy a key position in Aleksander Peczenik's thinking. It would be quite justified to say that these concepts are the most contested of his constructs. The doctrine of transformation has been much discussed in international philosophy of law. There are many serious misunderstandings regarding this concept. In order to give the reader a better possibility of proper understanding this doctrine, I shall deliberately simplify it. 
Let us assume an interpretative situation in which A, who is interpreting a law, has reached a result, R, supported by a certain justification, J. The problem is how $\mathrm{R}$ follows from $\mathrm{J}$. Is there a bridge that connects the justification with the result? In legal interpretation, justification is based on sources of law, such as statutes, precedents, legislative materials etc. How is it possible to reach a certain interpretation with the help of sources of law? In this connection, Jerzy Wróblewski has written about two types of justification, internal and external. Both belong to contextually sufficient justification.

Wróblewski describes internal justification schematically:

$$
\begin{aligned}
& \mathrm{S} 1 \ldots \mathrm{Sn} \\
& \mathrm{I} 1 \ldots \mathrm{In} \\
& \mathrm{V} 1 \ldots \mathrm{Vn} \\
& \mathrm{R}
\end{aligned}
$$

In this diagram, $\mathrm{S}$ stands for the sources of law, including the interpreted statute, together with relevant factual circumstances; I stands for rules and principles of legal interpretation; V stands for valuations and R stands for the juristic conclusion. Wróblewski's diagram provides the following information. Internal justification is guided by rules. Its result is a deductive consequence of the justification. On the other hand, legal interpretation often requires valuation. This is necessary, e.g., because the sources of law must be placed in a certain order of priority. Moreover, the person interpreting the law may be forced to rely upon analogy. In other cases he must rely on moral grounds, and so on. In this way, valuations are to be found in the justificatory material.

It is always possible to reconstruct (ex post facto) the internal justification as a logically correct inference, where the conclusion follows from a certain legal norm, the factual material, certain rules of legal interpretation and a valuation. The problem remains, however, why the premises have been stated precisely in the actual way. Here we meet external justification, that is, justification of the choice of premises. One can argue that the really difficult problem of legal interpretation concerns the external justification. Let us recall legal certainty. The central demand of legal certainty is not fulfilled if the premises are selected arbitrarily.

The internal and the external justification jointly elucidate the concept of transformation. In our example, internal and external justification resulted in the transformation from the interpreted statute to the juristic conclusion, R. Let us ask why $\mathrm{A}$, in interpreting the statute, utilises a specific legal norm as his first premise. The legal norm need not match the wording of the statute. However, it is possible to refer to another source of law, for example to the travaux préparatoires or a precedent: in this way a new inference can be constructed; the first premise in the first inference is the conclusion of the second inference. This means that the first premise is justified by referring to a new source of law. In this way we get a chain of inferences that finally create acceptable external justification. The transformation has become justified.

The concept of "transformation" is only a practical way of describing certain key questions in legal interpretation. The central problem is whether legal interpretation 
is a purely deductive operation, or rather a puzzle in which various deductive inferences fit together in a reasonable, though not deductive way. Here we come to the key questions in Peczenik's work: coherence. All justification is a concrete whole. In this respect, justification is comparable to a puzzle where the different pieces find their proper place in the moment when one obtains a general view of the outlines of the figure. The difference between an ordinary puzzle and legal justification lies in the fact that the former has a predetermined picture while the latter is more problematic: it is impossible to demonstrate which picture is the correct one. The ultimate measure is whether or not the legal justification as a whole is accepted in legal society. The core of legal truth is to be found in this relativism.

9. The doctrine of transformation has also another dimension. Legal dogmatics interprets and the courts apply valid legal norms, that is the law in force. In everyday practice, there is no need to ask whether or not a legal norm is valid. The lawyers take for granted that it is. It would be even more strange to ask about the content of the concept of legal validity; only law theorists are interested in this question. On the other hand, it is the purpose of legal theory to construct a coherent total picture of the legal order. For this reason, the problem of the law in force is an important one for theorists.

Hans Kelsen's ideas about the structure of the legal order as a pyramid of norms provides a useful point of departure. According to Kelsen, a "lower" norm is (formally) valid if is it has been created on the basis of a higher norm; e.g., a law is in force if the Parliament has followed the Constitution when passing it. This relationship is thus not a logical one: a law is not a deductive conclusion of the Constitution. All legal norms can, in this way, be located in a norm pyramid, the top of which consists of the Constitution. The formal validity of norms can easily by examined by checking whether or not they belong to the pyramid. One central question, however, remains unanswered. How can the legal order be distinguished from other pyramids of norms? Are there any criteria that would make it possible for us to identify a legal order as a legal order, when compared for example with a pyramid of rules used by the Mafia? From the point of departure of legal theory, the question can also be formulated, as follows: How can the Constitution be justified? Hans Kelsen answered this question by assuming the so-called basic norm: the Constitution must be followed. Kelsen presented different versions of the content of the basic norm and its philosophical and logical status. Regardless of these variations, the basic norm is the "top" of the pyramid of legal norms. We must assume such a basic norm. Without this assumption, the chain of validity shall continue ad infinitum. All of this is acceptable. On the other hand, one can ask how an assumed basic norm can justify an order as a legal one. Why must we follow the Constitution?

Aleksander Peczenik has an answer to this question. The core of the answer lies in the fact that the law must "follow" in some way from certain non-legal social phenomena, that is, from social facts and valuations. The latter are transformed to the law. This can occur through the construction of a justifying basic norm: "If certain social facts $\mathrm{F}$ and social values $\mathrm{V}$ exist, then the basic norm must be followed." 
A system of rules can be a legal order only if it covers a certain territory, applies to all citizens, claims a monopoly of force, and so on.

As H.L.A. Hart has pointed out, a legal order must also have a minimum value content. We are not inclined to accept, e.g., Hitler's or Pol Pot's system of rules as true legal systems. The reason is that these systems violate what, for us, are vital basic values. For example, we hold that a Pol Pot cannot guarantee his citizens the legal certainty that is a requirement of a true legal order. For this reason, Peczenik deems it necessary to include valuations $(\mathrm{V})$ in the justifying basic norm.

At this stage, someone may ask whether the justifying basic norm must, in turn, be justified, and so on ad infinitum. Peczenik has answered that this is not necessary, and has referred to Neil MacCormick's ideas about so-called "underpinning reasons". These are necessary and fundamental conditions of identification of a system of rules as a legal order. For example, if we are willing to accept total chaos in society, it does not matter whether or not there are legal norms. The concept of "chaos" includes by definition that people in this case do not care about legal certainty. But if a society wants to avoid chaos, it must accept the justifying basic norm. Avoidance of chaos is thus an "underpinning reason" that breaks the chain of justification.

Here we come face to face another key problem in Peczenik's presentation. This "underpinning reason" is a moral reason. It is moral - at least prima facie - to avoid chaos. In this way, Peczenik formulates his statement: what is prima facie legal is also prima facie moral.

The transformation of non-legal phenomena to law is not an exception from the famous principle according to which it is impossible to derive norms from facts. This principle has been called "Hume's guillotine": the gap between what is and what should be cannot be bridged. The doctrine of transformation cannot be understood to say that the normative order is derived from a factual background. The constitution is not justified directly by facts, but instead by a justifying basic norm, and this norm refers to facts and values. However, this does not mean that the concept "justifying basic norms" is unproblematic. There are good reasons to discuss, e.g., the role of values in this construction. A critic could say that Peczenik mixes law and morality together, which results in ambiguity of the concept of law. For such a critic, legal validity is a purely legal concept, as it is in Hans Kelsen's pure theory of law. This discussion touches upon fundamental questions in law and morality. Aleksander Peczenik has answered these eternal questions in a well-formulated manner. The undeniable benefit of the doctrine of transformation lies in its clarity and emphasis of morality. In our times, one does not always recall that already Olaus Petri regarded morality as an integral part of law. Aleksander Peczenik continues this old Nordic tradition of thought in a modern form.

10. Let us return to the contextually sufficient justification in the law. As we were able to note, there are no clear criteria deciding when the chain of external justification in the law can be cut off. This means that we do not know if our justification is right or not. Yet, it has been quite common in legal theory to argue that there is always one right solution to all problems of legal interpretation. In later years, the most famous doctrine of the one right answer has been 
associated with Ronald Dworkin. Dworkin represents a weak version of this doctrine: he claims that there is always one right solution, but not that it is always found. An ideal judge ("Hercules J" in Dworkin's terminology), who fulfils the highest standards of impartiality, has full information and knows all the rules of interpretation, can find this one right solution.

Aleksander Peczenik criticises such theoretical models. Throughout his entire long career in legal science, Peczenik has sought to formulate a legal theory that, without fundamental or practical weaknesses, would recognise that a legal norm can be interpreted in more than one way. To this end he has developed the concept of "deep justification" by asking under what circumstances legal interpretation can be justified. This question, again, concerns the place of valuations in the interpretative process.

Peczenik has the same point of departure as Wróblewski. In many ways, valuations are built in into legal justification. But why does this insight justify a criticism of the doctrine of the one right solution? The reason is a simple one. If we accept the theory of objective values, then Dworkin's line of thought is acceptable. In such a case, Hercules $\mathbf{J}$ is capable of discovering these values. He can possess knowledge about objective values. Peczenik, however, is a value relativist. He denies that there are objective values. To be sure, he writes about "good-making facts", but these merely tell us what is prima-facie valuable. A definitive, all-things-considered, value cannot be derived from empirical facts. Different valuations can compete in society, and it is impossible to demonstrate that any one of these is false.

Since values are an integral part of legal interpretation, and often play a key role in interpretative activity, it is natural to reject the doctrine of the one right solution. A certain interpretation I1 can be based on certain valuations, whole another interpretation can be based on another set of valuations. In such cases legal "truth" is relative in respect of the background valuations. Does this mean that, ultimately, legal interpretation is arbitrary? Are there as many interpretations as there are interpreters of the law?

11. Before we discuss this problem, it is necessary to define our terms more precisely. The difference between various interpretations can in practice often be explained by factors other than valuations. The person interpreting the law can have insufficient knowledge about sources of law, and he may perhaps be careless in his use of interpretative rules. It may also happen that his terminology is unclear, vague or ambiguous. But such random elements have been eliminated from Peczenik's model, since the person interpreting the law is assumed to be reasonable. On the other hand, it is important to emphasise the difference between feelings and valuations. The former are not open to discussion. Feelings can be compared to tinted glasses. They form prejudices that hamper a reasonable discussion. On the other hand, a feature typical for valuations is that they can be based on reasons, within certain limits. This feature is characteristic of both instrumental and so-called basic or intrinsic values.

An instrumental value is involved when, for example, one says that "this is a good axe". The property of being good is a feature of the axe. It is instrumental 
when it is possible to use the axe as a tool for achieving a goal. Statements that connect this property with the axe express an instrumental valuation. It is always possible to ask "why?", or in other words to study what reasons justify the statement referring to the goodness of the axe. The answer refers to the result that can be achieved with the help of the axe.

A basic value, such as equality, is something else. It is not a mere instrument for achieving something "external". Instead, it is a goal in itself. Despite this, a basic value can be justified. One can ask "why?" and receive certain reasons for the valuation. However, somewhere there is a limit that cannot be passed. The chain of justification must be cut off: something is good because it IS good. Here we find the core of value relativism. Many incompatible chains of justification are possible. One can assume more than one justified perspective.

12. We have always assumed that the person interpreting the law and his adverse party - the person posing the legal question - are behaving as reasonable people. If we do not accept this assumption, we cannot avoid arbitrariness, and thus we cannot achieve legal certainty. Law and reason is therefore a well chosen title for a book that deals with models for legal justification.

Let us, e. g., assume an enactment L1 for which five different semantic (linguistically possible) alternative interpretations can be presented. On the basis of the sources of law and the rules of legal interpretation three of the semantic possibilities (11-13) can preliminarily be eliminated. Thus, the legal material leaves open the final choice between 14 and 15. Legally, the sources of law justify both alternatives. In this situation, the final interpretation will be based (at least in part) on valuations, in other words on a certain assumed priority order among sources of law. Rationality is involved both when the legally "impossible" alternatives (11-13) are eliminated and when the final choice is made between the remaining interpretations. If the activity of the person interpreting the law had not fulfilled the general criteria of rationality, we would not be willing to accept the interpretation as legal. Why not? The reason is simple. The legal interpretation must guarantee predictable results and a non-rational decision is not predictable.

A great deal of Aleksander Peczenik's work thus consists of an analysis of the concept of rationality. Peczenik has reformulated and modified the criteria of rationality that Robert Alexy originally established in his monumental work, "Theorie der juristischen Argumentation" (1978). Peczenik defines rationality with the help of certain general principles and such concepts as "support" and "coherence". Rationality is bound by criteria and principles of coherence, for example the principle demanding generality of justification. At the same time, this does not imply that Peczenik would accept a rationalist doctrine of natural law. He does not suggest that a reasonable person can always discover the objective values. Rationality guarantees that interpretative activity is reasonable, but it permits the two reasonable to evaluate differently.

Law, morality and reason are thus combined. The connection is not a result of arbitrary definitions, assumed by law theorists. It is based on our concepts, inter alia on everything that we deem legal in our Western legal culture. Not only law 
and morality, but also the concept of "reason" are cultural phenomena. They assume that certain moral and rational demands are fulfilled in legal interpretation.

On the other hand, Peczenik does not intend to argue that people are reasonable or that, as a result of certain development, they will become reasonable. People try to be reasonable and make mistakes. Rationality is an ideal that can be realised more or less. Despite this, human culture needs such a measure, among other things in order to know what is just and what is not, and to identify the optimal framework for action. To be sure, the demand for rationality changes along with the development of society. We do not think today in the same way as did the inhabitants of the Roman Empire 2000 years ago, even though we have inherited the Roman tradition. In particular, we cannot demonstrate that reason is an integral (necessary) element of the definition of man or that we are rational due to our nature. But it is the case that our language and our concepts are constructed so that we expect that judges shall behave in a rational manner. In this sense, the concept of rationality is a necessary element of our culture.

13. Different valuations are not the only source of differences in legal interpretation. If we disregard insufficient knowledge about the sources of law and linguistic usage, there still remains a fundamental basis for differences in interpretation. Different interpretations can be based on different theoretical concepts. Here we meet the second function of legal dogmatics, the systematisation of legal norms.

Concepts are used in all human thinking. One of the most important goals of scientific activity is to construct concepts. The same is true of legal dogmatics. Theoretical concepts and theories are tools of presentation of scientific results. They are also instruments for thinking about the objects of experience. Let us say, for example, that in front of us there is an object that we call a "chair". Nothing is a chair without the concept of "chair". We analyse and systematise a certain complex of facts with the help of this concept. For us, the world as it is because we use such analytical tools. The concept of "resistance" in the study of electricity is another good example. Without the concept, it is not possible for us to identify such a phenomenon. All that we can do is to note the results of certain measurements our instruments give us. These are then interpreted with the help of the concept of "resistance". Thus, the concept is a scientific tool for capturing and making sense of reality.

In the legal field, concepts and constructions of concepts have a similar position. In civil law, we speak about the invalidity of an agreement. During the 1950s, the Finish analytical school developed this concept in a very detailed manner. The view was formulated that the invalidity could be either (a) absolute or relative, depending on which group of persons was in question (contra omnes or inter partes), (b) final or subject to correction through, e.g., acceptance of the agreement, (c) to be stated ex officio or only on the basis of a complaint, a claim and so on. The point was that one could not ask in general whether or not an agreement was valid; instead, one had to ask in what sense an agreement could be called invalid. In this way, we find an increasing number of ways of asking questions, and more sophisticated questions 
provide better possibilities of analysing the legal situation. The dichotomy between valid and invalid is too schematic in complicated legal conflicts, even if it is sufficient in typical cases.

This means that our knowledge of law depends on our concepts. Formation of concepts normally requires systematisation of phenomena. As we have already noted, there is a necessary connection between systematisation and interpretation. Legal interpretation is impossible without the formation of concepts, while practical systematisation must often be corrected by interpretation. This is the case when interpretation needs more precise concepts than those that can be provided by the prevailing theory. There is thus an interplay between interpretation and systematisation. This interplay ultimately and finally produces the coherence that is so important for Peczenik's model of thinking.

14. This is a particularly important phenomenon when we try to understand the growth and progress of legal dogmatics. If one asks whether legal dogmatics has made any progress over the past 100 years, the answer can be formulated only with reference to the change of the legal concepts. A progress of legal dogmatics would not be possible without conceptual change. Peczenik's theory of coherence provides some criteria for evaluation of conceptual changes. On the other hand, two persons interpreting the law may highly fulfil all the demands of rationality and coherence, and yet reach different results, due to the fact that they use different concepts. It is thus possible for person A, interpreting the law, to deem an agreement to be null and void, and for person B to deny this. The reason for the disagreement can be that, for B, "null and void" refers only to invalidity that is absolute, final and ex officio, while A understands this concept as covering some other types of invalidity as well.

When Aleksander Peczenik analyses the legal paradigm, the law as a cultural phenomenon, and the demands of coherence, he deals with these basis problems. He has succeeded in his book in combining the analysis of legal interpretation with the most central philosophical, moral and cultural problems of our time. For this reason, Peczenik's present work is one of the most important contributions to the Nordic theory of law. 